\title{
Evidence of pathogenic zoonotic tick-borne Rickettsia and Borrelia spp. in some communal farms in the Eastern Cape Province, South Africa
}

Olusesan Adeyemi Adelabu ( $\square$ olusesanadelabu@gmail.com )

University of Fort Hare https://orcid.org/0000-0003-4858-9136

Benson Chuks Iweriebor

Sefako Makgatho Health Sciences University

Anthony Ifeanyi Okoh

University of Fort Hare

Larry Chikwelu Obi

Sefako Makgatho Health Sciences University

Research article

Keywords: Rickettsia, Borrelia, Zoonotic, Emerging, Domesticated, South Africa

Posted Date: December 16th, 2019

DOl: https://doi.org/10.21203/rs.2.18929/v1

License: (c) (1) This work is licensed under a Creative Commons Attribution 4.0 International License. Read Full License 


\section{Abstract}

\section{Background}

The abundance of tick populations in South Africa represents a probable risk for both animal and human health. Rickettsia and Borrelia are well-known significant agents of emerging human tickborne infectious diseases throughout the world. Nevertheless, the epidemiology of their infections has been underreported in South Africa, Therefore, the aim of this study was to profile for zoonotic Rickettsia and Borrelia species from ticks infesting domesticated animals in the Eastern Cape, South Africa. Morphological and molecular identification techniques were conducted on 1,200 tick samples collected from domestic animals before screening for the target bacterial pathogens.

\section{Results}

The molecular identification of the tick samples was based on the amplification of the 12S rRNA mitochondrial DNA while detection of Rickettsia and Borrelia species were carried out by amplifying fragments of $g / t \mathrm{~A}$, ompA and ompB genes for Rickettsia and flaB gene for Borrelia spp. Thereafter, the positive ticks, Borrelia and Rickettsia ompB amplicons were sequenced and further analysed. Eight species of ticks belonging to three genera; Rhipicephalus, Amblyomma, and Haemaphysalis were identified. A total of $320(27 \%)$ samples were confirmed positive for Rickettsia out of which $74(23 \%)$ were positive for both ompA and $o m p B$ genes. Phylogenetic analysis of $o m p B$ revealed a high homology to rickettsial reference strains from GenBank, while there was no positive result for Borrelia. The generated sequences showed 99.1 to $100 \%$ homology with $R$. africae KX227790 (100\%), R. parkeri-KY113111 (99.8\%), R.peacock $(99.3 \%)$ and $R$. slovaca - KJ675445, JX683122 (99.1\%) representative sequences in GenBank.

\section{Conclusion}

The findings from this study revealed that ticks collected from domesticated animals were parasitized by Rickettsia species with possible zoonotic potential, which is detrimental to human health if bitten by infected ticks.

\section{Background}

Vector-borne diseases constitute a serious risk to human health causing substantial morbidity and mortality worldwide ${ }^{1,2}$. Ticks are haematophagous ectoparasites of vertebrates that obtain their nutrition by feeding on blood, hence, they have been described as competent vectors of diseases, and over $10 \%$ of the currently known population of tick species have been described to be of medical or veterinary significance ${ }^{3,4}$.

After mosquitoes, ticks are considered the second most important vectors of human diseases and the major vectors of pathogenic organisms in animals ${ }^{5}$, as well as the most important vectors for numerous severe zoonotic infections worldwide ${ }^{6}$. Also, an increase in the range of tick-borne diseases infecting domestic 
animals and humans has been observed recently, and several significant zoonotic TBDs such as rickettsioses ${ }^{7}$, and Lyme borreliosis ${ }^{8}$ are on the increase, worldwide. Tick-borne pathogens (TBPs) have been reported to maintain lifecycles that include ticks and animals and sometimes they are transmitted to infested humans who are usually the dead-end hosts ${ }^{9}$.

Rickettsia and Borrelia spp. are both transmitted by ticks and are among the numerous zoonotic pathogens responsible for febrile illness and sometimes death among humans. Rickettsial diseases, caused by organisms of the genus Rickettsia are classified into three biogroups: spotted fever group (SFG) which includes Rocky Mountain spotted fever (RMSF) and rickettsial pox caused by $R$. rickettsia and $R$. akari respectively, as well as other spotted fevers such as Boutonneuse fever (Mediterranean spotted fever, Kenya tick-bite fever, Israeli spotted fever, African tick typhus, Marseilles fever, and Indian tick typhus,) caused by several other Rickettsia species.

Second is the typhus group (TG) ricketssiae which are responsible for similar diseases but with a different epidemiology ${ }^{10}$ and the etiologic agents are $R$. typhi and $R$. prowazekii, although they have been described to be similar to causative agents for the spotted fever group but are distinct antigenically ${ }^{11}$. Lastly, the scrub typhus biogroup, a single taxonomic name (Orientia tsutsugamushi) has been described for the rickettsial agents of this biogroup. Nevertheless, these pathogens represent a diverse collection of pathogens that are extremely different from Rickettsia spp. of the typhus and spotted fever groups; hence they have three major serotypes which are Karp, Gilliam, and Kato ${ }^{12,13}$.

However, a re-classification pattern for Rickettsia, with the inclusion of a fourth family has been proposed, which is known as transitional group (TRG) Rickettsiae. It is distinctive from SFG and TG Rickettsiae and harbours genes from likely interactions with TG Rickettsiae through conjugation ${ }^{14}$. Rickettsial diseases have been reported to be very challenging to diagnose, owing to their similar symptoms and epidemiology shared with several other febrile illnesses. Thus, the overall reported cases of rickettsial diseases are probably inaccurate as they are often times underreported ${ }^{15,16}$.

Borrelia, a genus of bacteria belonging to the spirochete phylum ${ }^{17}$, a causative agent of borreliosis and a zoonotic infectious disease transmitted by ticks. Over 50 species of Borrelia have been categorized into two groups, the first group comprises of about 21 species transmitted by the hard ticks, within Borrelia burgdorferi sensu lato complex, and is related with Lyme borreliosis group, while 19 species are described to be mainly transmitted by soft ticks associated with relapsing fever group with exception of the human louse-borne Borrelia recurrentis ${ }^{18}$. Borrelia species exist in enzootic cycles mostly involving ticks and several animals and bird hosts.

Most hard-bodied ticks belonging to genus Ixodes have been described to be major vectors transmitting pathogenic Borrelia spp. with I. scapularis transmitting B. burgdorferi in the midAtlantic, East, and upper Midwest of United State while I. pacificus transmitting B. bissettii and $B$. burgdorferi in the Western parts of USA, whereas in European, I. ricinus is known as a major vector for $B$. afzelii, $B$. burgdorferi, and B. garinii along with other non-pathogenic and potentially pathogenic Borrelia spp., and I. persulcatus, whose geographical distribution has been described to some 
extent overlaps with I. ricinus, which is a known vector of $B$. garinii and $B$. afzelii in eastern regions of Asia and Europe ${ }^{19,20}$.

Owing to expansion in geographical boundaries by ticks into new ecological terrains worldwide, severally described Rickettsia spp. and Borrelia spp. that were previously considered to be endemic to a particular geographical location are now being described from different parts of the world and in different ticks ${ }^{21}$. The understanding of bacteria transmitted by ticks (potential reservoirs and vectors of microorganisms) in a given geographical location is a valuable marker for assessing the risk of infection in both humans and animals. This study therefore was aimed at investigating the prevalence of TBPs of Rickettsia and Borrelia spp. in ticks parasitizing domesticated animals in the Amatole and O.R Tambo District Municipalities of Eastern Cape, South Africa.

\section{Results}

A total of 1,200 ticks were mechanically removed from domesticated ruminants $(718,130$ and 352 from cattle, sheep and goats respectively) from selected communal farms from Amatole and O.R Tambo District Municipalities. Nineteen species of ticks belonging to thre genera; Rhipicephalus, Amblyomma and Haemaphysalis were identified in this study (Table 1), with Amblyomma hebraeum having the highest occurrence of 335 (27.9\%), followed by Rh. appendiculatus; 274 (22.8\%), Rhipicephalus decoloratus, 224 (18.7\%) and Rhipicephalus eversti eversti; 200 (16.7\%). For Rickettsia species, 320 (27\%) genetic materials (DNA) were confirmed positive for Rickettsia citrate encoding synthase (g/tA) gene, out of which 74 (23\%) were further confirmed positive for both ompA and ompB gene while none was detected for Borrelia. A homology search for the generated sequences from the PCR data revealed a high percentage of identity between $96 \%$ - 100\% with other homologous ompB of other Rickettsia sequences in GenBank (Table 2).

\section{Molecular detection of zoonotic tickborne bacterial pathogens}

For Rickettsia species, 320 (27\%) genetic materials (DNA) were confirmed positive for Rickettsia citrate encoding synthase ( $g / t A)$ gene, out of which 74 (23\%) were further confirmed positive for both ompA and ompB gene, while no positive sample was confirmed for Borrelia. A homology search for the generated sequences from this study revealed a high percentage of identity between $96 \%$ - $100 \%$ with other homologous ompB of other Rickettsia sequences in GenBank (Table 2).

The derived Rickettsia (ompB) sequences were further subjected to phylogenetic analyses with the following Rickettsia ompB reference strains from GenBank: KX227791- $R$. africae (Kenya), KU721071- $R$. africae (Austria), AF123721- R. conorii (France), AF149110- R. conorii (Australia), KF660534- R. africae (Kenya), KY124259-R. parkeri (USA), AF123726 (India), KY113111 (USA), KX891187 (South Africa), KY924884 (Ethopia), KX227788- R. conorii (Kenya), KU721071- R. africae (Tanzania), KT032137- Rickettsia sp. (Djibouti), KF660535- $R$. africae (Kenya), KT032137- Rickettsia sp. (USA), AF123722- R. sibirica (France), LT558854- Candidatus Rickettsia wissemanii (French Guiana), EF219461- Rickettsia sp. (Taiwan), CP001612- $R$. africae (France), X16353- Rickettsia rickettsii (USA), HQ232253- Rickettsia raoultii (Germany), AF123706- $R$. africae (France), CP003311- Rickettsia rickettsii (USA), EF219464- Rickettsia sp. (Taiwan), 
JQ792107- Rickettsia raoultii (China), KT835128- Rickettsia sp. (South Africa), CP003306- Rickettsia rickettsii (Colombia), KJ619633- $R$. africae (Gabon), KT835081- Rickettsia sp. (South Africa), LT558854Candidatus Rickettsia wissemanii (Guiana), KY124259- R.parkeri (Western USA), AF123726-R.conorii (France), JX683122- R. slovaca (Romania), KJ675443-R. peacockii (Italy), EF219464-R.Rickettsia (Taiwan). The reference sequences were previously aligned with the derived sequences, using ClustalW in MEGA 7.0. version software (Kumar and Tamura, 2016), before generating the phylogenetic tree as shown in Figure 4.

\section{Phylogenetic Analysis of rickettsial pathogens using ompB gene}

Phylogenetic analysis showed that the obtained sequences clustered into three clades with other reference sequences from different geographical regions of the world. 26 sequences clustered in one clade with reference sequences from USA, France, Italy, Austria, Kenya and Gabon, with accession number LT558854Candidatus Rickettsia wissemanii, KY124259-R.parkeri, AF123722-R.sibirica, EF21946 1-Rickettsia sp., KJ675443-R.peacockii, AF123721-R.conorii, KJ619633-Rickettsia sp. A598, AF123722-R.sibirica, KT032137uncultured Rickettsia sp., KX227791-R. africae, KX227788-R. africae, and AF123706- $R$. africae. 44 sequences were found to cluster in another clade with each other, while two other sequences clustered in another clade closely with $R$. rikettsii- X16353, $R$. conorii-AF149110, and R.africae-KF660535 reference sequences from Australia, South Africa, Romania, and Germany with high genetic similarities (Fig 4).

\section{Phylogenetic analysis of tick species}

Phylogenetic analysis of generated tick sequences showed that the four genera; Rhipicephalus, Amblyomma, Haemaphysalis and Boophilus that were initially identified through morphologic criteria, clustered with different corresponding species of the reference sequences (Fig 5). Sequence T21 was shown to clustered in one clade with reference sequences KC503255-Rh.australis, KC503261-Rh.microplus, KC503259- Rh.microplus, and AB075954- Haemaphysalis sp. Also, the following obtained sequences; T29, T48, T29 were found to cluster closely with reference strain AF031859-Rh.appendiculatus, DQ801282Rh.appendiculatus, KX276945-Rh.appendiculatus, DQ849237-Rh.zambeziensis, DQ849224-

Rh.zambeziensis, MF3611814-Rhipicephalis sp., MF479197-Rh.appendiculatus. Likewise, sequence T01, $\mathrm{T} 4, \mathrm{~T} 13, \mathrm{~T} 20, \mathrm{~T} 25$, and T32 clustered together and were found to cluster together in another clade with reference sequence KF583637-H.longicornis, AF31853-H.longicornis, HQ434625-H.longicornis, AF150049A.hebraeum, MG076932-A.maculatum, AY342288-A.triste, AY342261-Amblyomma sp., KT386309Amblyomma sp. AF150049-A. hebraeum. In addition, obtained sequence T40 revealed high closeness to reference sequence MF479198-Rh. evertsi, AF150052- $R$ h. evertsi, MF348105- $R$ h. evertsi while sequence T10 was found to be closely related to KY676830-Rh.australis, EU9217770-Rh.microplus, AF150045B.annulatus, and AF031847-B.microplus.

The nucleotides sequences generated from this study were submitted to GenBank under the following accession numbers; MK347112 - MK347185, for Rickettsia, while eight representative sequences were deposited for Amblyomma hebraeum, Rhipicephalus microplus, Boophilus annulata, Haemaphysalis longicornis under accession number MK347205 - MK347212. 


\section{Discussion}

Majority of people living in South Africa rural settlements are in close proximity with tick-infested ruminants, hence they are at high risk of being infected with arthropod-borne zoonotic pathogens. In addition, several cases of arthropod-borne diseases are commonly reported, especially in international travellers returning from South Africa, hence it is expedient to be aware of new vectors, host and pathogens ${ }^{30}$.

Although, the detection of arthropod-borne pathogens in ticks that infest animals cannot automatically demonstrate the role of the host as reservoir or the tick as vector, however, both can hypothetically act as amplifiers, and are important for the epidemiology of tick-related infections ${ }^{31}$.

In this study, a total of 1200 ticks comprising both adult and nymph that were mechanically removed from farm animals belonged to three genera; Rhipicephalus, Amblyomma, and Haemaphysalis were identified, with Rhipicephalus having the highest occurrence of 853 (71.1\%), followed by Amblyomma; 335 (27.9\%), and Haemaphysalis; 12 (1\%) (Fig. 2). The three genera had previously been reported from South Africa ${ }^{32,33}$, thus our results is a confirmation that these genera are the predominant ticks species in the study areas. The emergence and geographical distribution of tick-borne zoonotic pathogens are controlled by the ecological distribution of their arthropod vectors.

Of recent, newly discovered species of arthropod-borne diseases are continually being added to the variety of groups of tick families/genera, owing to their chemical, physical and immunological features ${ }^{34}$ which has made the species in each genus becoming endless, especially the species with zoonotic potentials. Globally, various species of Amblyomma have been reported to be vectors of both animal and human rickettsial pathogens, which have resulted in increased risk of spotted fever group (SFG) rickettsiosis of late 49 . As a rare acute and multi-systemic febrile disease, spotted fever has been described to have mortality rate of over $50 \%$ in the absence of proper prophylaxis (Prado et al., 2018). A. hebraeum with a significant aggression for biting humans has been documented as a well-known vector of Rickettsia africae, a zoonotic tick-borne bacterial pathogen that is the etiologic agent of African tick-bite fever in sub-Sahara Africa with a morbidity rate of $>50 \%{ }^{47}$. Thus, R. africae infection has been described, after malaria, to be liable for most febrile illnesses diagnosed in tourists returning from southern Africa ${ }^{21,34}$.

In addition, various species of Rhipicephalus and Haemaphysalis have also been documented in several geographical regions of the world to be vectors for various zoonotic tick-borne pathogens. R. massiliae, was first isolated from Rhipicephalus sanguineus (brown dog tick) in Europe, and it has been implicated in human cases of spotted fever in South America, Argentina and Europe ${ }^{35,35}$.

The abundance of Rhipicephalus species in many West African countries has been described as currently have a magnitude higher than Amblyomma species (Biguezoton et al., 2016), which was formerly known as the main vector of heartwater Ehrlichia ruminantium in the region. Over $70 \%$ of total number of Rhipicephalus genus has been described to be endemic to Afrotropical region. It has also been implicated in human cases of monocytic ehrlichiosis and Mediterranean spotted fever ${ }^{37,38}$. 
Several mammals have been reported to be infested by Haemaphysalis ticks in countries like Italy, Turkey, Greece, Spain, Cyprus and Croatia 39,40,41,42, resulting in various bacterial, protozoan and viral infections. Haemaphysalis ticks have also been implicated as vector of human bacterial infections in Australia and China ${ }^{43,44}$. Sarih et al. ${ }^{45}$, also reported Haemaphysalis ticks as being responsible for transmission of spotted fever group rickettsiosis in Morocco.

Furthermore, about nine pathogenic Rickettsia species (R. africae, R. parkeri, R. mongolotimonae, R. conorii, R. honei, R. rickettsii, R. raoultii, R. australis, and R. rhipicephalis) belonging to the spotted fever group Rickettsiae were detected in different tick samples collected in this study. R. africae had been previously reported from ticks removed from different animals and humans in South Africa, thus its detection was expected $^{34,46,47}$ from its well-known vector; A. hebraeum. Subsequently, about 24 sequences, from the 74 obtained sequences for ompB gene of Rickettsia sp., showed between $98.9 \%-99.3 \%$ homology with Rickettsia parkeri (KY124259, CP003341, AF123717, and KY1131111).

Rickettsia africae, a causative agent of African tick-bite fever (ATBF), belonging to Spotted Fever Group (SFG) Rickettsia, has been described as an emerging infectious pathogen in the African continent, affecting both humans and animals with devastating effects on livestock production and human health. Several seroepidemiological studies across the continent have described residence in livestock production areas as the major risk factor for seropositivity in rickettsiosis antigen 48,49 .

The risk has been attributed to the abundance of Amblyomma sp. in most African countries ${ }^{50}$, as species of Amblyomma have severally been implicated as vectors of R. africae infection, hence the increase in percentage of infected ticks could increase the probability of humans being bitten by them thereby leading to increased rate of human rickettsisosis.

ATBF has also been recovered from American travellers returning from Southern Africa ${ }^{51}$, with a history of tick bite during their adventure, as well as positive human serum samples in western Africa ${ }^{52}$. The detection of R. africae in the present study is supported by the findings of Mediannikov et al. ${ }^{52}$ who reported high detection rate of R.africae from species of Amblyomma ticks collected from domesticated animals.

In addition, the first detection of R. africae, the most widespread spotted fever agent in sub-Saharan Africa, has recently been described in Corsica, France ${ }^{53}$, through PCR, from ticks that were manually removed from cattle. Kernif et al. ${ }^{54}$ also reported the detection of R. africae from Amblyomma specie in Algeria, using gltA and ompA gene amplification by PCR. In the same way, Keller et al. ${ }^{49}$ equally reported a high incidence of R. africae from Amblyomma ticks, which have directly led to the human rickettsiosis among pregnant women, although in low incidence rate.

Similarly, the detection of R. africae by PCR on a skin biopsy of a returning 40-year-old Italian physician from Zimbabwe, who presented with fever, a tache noire on the left leg, and a neurological syndrome characterized by severe pain of the left leg was reported by Zammarchi et al. ${ }^{55}$. The global incidence rate of human rickettsisosis caused by $\mathrm{R}$. africae has been reported to be above $5 \%$ among travellers in whom acute febrile infection developed after their returning from sub-Saharan Africa 52 . 
The presence of R. africae from A. hebraeum and species of Haemaphysalis and Rhipicephalus has long been established in South Africa ${ }^{31,46}$, hence South Africa has been described as an endemic region for ATBF.

Rickettsia parkeri, the causative agent of spotted fever rickettsiosis in human, was first discovered to parasitize A. maculatum ticks in the United State in $2004{ }^{56}$ with infection in humans having similar clinical symptoms with R. rickettsii. Infection of humans living in the Gulf Coast tick endemic region of USA is very high as clinical specimen of twelve patients living in the endemic region that were submitted for laboratory evaluation confirmed six samples positive for R. parkeri, the etiologic agent of spotted fever rickettsiosis ${ }^{57}$.

R. parkeri has also been described as a causative agent of human rickettsiosis in other countries like Argentina ${ }^{58}$ and Brazil ${ }^{59}$ with Amblyomma triste ticks haven been implicated as vectors for this infection ${ }^{60}$. Similarly, Faccini-Martínez et al. ${ }^{61}$ reported a case of R. parkeri infection from a Spanish traveller returning from Uruguay, who was confirmed bitten previously by Amblyomma triste tick, hence, it has been described to be the second most important cause of tick-borne rickettsiosis in the United States, Argentina and Brazil, after R. rickettsia ${ }^{60,62}$.

Until now, R. parkeri has not been reported to infect humans in African continent; hence this is the first report of its existence in the continent, although from tick sample. However with the zoonotic potential of R. parkeri which has been described from other continents, it is expedient for the public to be aware of its existence and the appropriate authority to expedite action in preventing its outbreak.

Another spotted fever group pathogenic Rickettsia detected in this study was R. mongolotimonae which was first recovered from Hyalomma asiaticum tick from France in $1991^{63}$ and in 1996, its pathogenicity in humans was first described in a female patient with an atypical tick-transmitted disease, followed by another human case from a 49 year old HIV patient in $1998{ }^{64}$. A similar human case was described in Greece from another immune-compromised patient, who reported no contact with animal except working in the field where he was collecting olives. During his hospitalization, an engorged female Hyalomma anatolicum tick was recovered from his scrotum by the physician ${ }^{65}$.

In addition, human cases of R. mongolotimonae have recently been reported in Sri Lanka from a 30-year-old female who returned from travelling to a jungle and was examined as an outpatient for fever ${ }^{66}$ and also in Cameroon, from a 54-year-old woman who presented a clinical symptoms of fever, headache, chills, myalgia and arthralgia ${ }^{67}$. Generally, R. mongolitimonae infection has been described to cause a mild, less fatal disease, nevertheless some complications have been reported, such as disseminated intravascular coagulation, shock, neurological disorders, atrial fibrillation, retinal vasculitis and acute renal failure ${ }^{68}$.

Pretorius and Birtles ${ }^{69}$ also reported the first human case of R. mongolotimonae, in South Africa, from a 34 year old patient who developed a severe headache and high fever, after he discovered a lesion on his right foot. This rickettsiosis was linked to bite from $\mathrm{H}$. truncatum with high endemicity in the region where the patient had been working and is known to parasitize humans ${ }^{70}$. 
Other Rickettsia species associated with human diseases that have been described in South Africa include R. conorii and R. sibirica which are etiologic agents of African tick bite fever ${ }^{69}$. Despite the emergence and re-emergence of various species of Rickettsia with potential zoonosis, rickettsiosis is still considered as a neglected disease ${ }^{21}$.

Furthermore, R. conorii, R. honei, R. rickettsii, R. raoultii were other related SFG pathogenic Rickettsia detected in this study. These SFG rickettsial pathogens have been described in several geographical regions of the world such as; USA ${ }^{10,71}$,Europe ${ }^{63,72}$ Australia ${ }^{73}$ as well as Asia ${ }^{74,75}$ to infest both humans and animals, hence their prevalence is on the increase, globally.

In addition, R. australis, and R.rhipicephali are other closely related Rickettsia spp. found in the United States, Brazil, Italy, Uruguay, China and Australia $76,77,78,79,80$.These obligate intracellular Gram negative bacteria have been associated with human infections, which still remain underdiagnosed and underreported especially in poorly scientific resource countries ${ }^{81}$, hence the pathogenicity, prevalence, and diversity of different arthropod-borne agents is still not well understood ${ }^{82}$ pointing out the need for a systemic microbial surveillance in tick vectors.

A study conducted in Kenya by Kimita et al. ${ }^{83}$ reported that a partial fragment of ompB gene was found to be most identical to Rickettsia rhipicephalus with $99.0 \%$ homology as against a required homology of $99.2 \%$ to qualify it as R. rhipicephalus, thus suggesting the probability of R. rhipicephalus circulating in African continent.

Based on phylogenetic data, two rickettsial isolates from this study were found to be closely clustered with R. conorii (AF149110 and AF123726) from Australia and India respectively (Fig. 4), this is supported by the findings of Essbauer et al. ${ }^{21}$ who reported, for the first time, $16 \%$ prevalence of pathogenic R. conorri from rodent with zoonotic potential in South Africa, It had also been reported in Algeria ${ }^{84}$.

Rhipicephalus spp. has been described as the main arthropod vectors for this bacterium in different geographical regions, which could probably be distributed by migratory birds and wild animals. Similarly, human infections with R. conorri have been described in some European countries such as France, Spain, Portugal, and Greece $3,63,85,86,87$. Fournier et al. ${ }^{88}$ (1998), also reported the detection of R. conorri from French athletes, who returned from South Africa and presented with headache, fever, regional lymphadenopathies, and multiple inoculation eschars.

The detection of R. conorri in different Rhipicephalus spp. in the study areas implies a wide-ranging of its host and ecological variation which does have epidemiological consequences. Also, the populace living in proximity with domesticated animals, in the study area is at high risk of rickettsial infections, if bitten by infected ticks, as the presence of genetic materials of the organisms detected in this study indicates probable zoonotic potential, hence systematic study is further required to establish the detection of these pathogens from human samples. 
Several studies on ticks have been previously conducted in South Africa, which have shown that varieties of SFG are in circulation in the country ${ }^{89,90}$. Similarly, a recent study conducted by Essbauer et al. ${ }^{21}$ showed that different species of pathogenic Rickettsia are in circulation in the country.

The most predominant tick species in this study was Amblyomma hebraeum and it had been formerly reported to be among the prevalent arthropod-vectors parasitizing different animals in South Africa, especially in the Eastern Cape ${ }^{32,90,91}$ followed by Rhipicephalus species ${ }^{33,92}$. The detection of R. africae genetic material in A. hebraeum and Riphicephalis species in this study is corroborated by the findings of Yawa et al. ${ }^{32}$, thus confirming the role of $A$.hebraeum and Riphicephalis spp. in the epidemiology of spotted fever group Rickettsia.

Findings from the study showed that the domesticated animals lived in close proximity with humans in the study area, apart from being released to graze freely in the vegetation, thus increasing the possibility of zoonosis from infected ticks to humans. Equally, with the increased prevalence of immuno-compromised individual in this region, rickettsioses could probably act as an opportunist infections taking advantage of their medical condition and aggravate their delicate health conditions. South Africa has been considered as destination for many tourists of which many have been diagnosed of rickettsiosis upon returning to their countries; hence the incidence of rickettsioses among travellers from sub-Saharan Africa is put at $21 \% 93$. Also, Dzelalija et al. ${ }^{96}$ through GeoSentinel Surveillance Network reported SFG rickettsiosis among Croatian travellers to be $82.5 \%$, thus confirming the potentiality of zoonosis of ticks, particularly when the prevalent tick species (Amblyomma hebraeum and Riphicephalus species) infest humans.

\section{Conclusion}

This study revealed the diversity of Rickettsia spp. and presence of R. parkeri, R. australis, and R.mongolotimonae; all belonging to the SFG Rickettsia for the first time in the Eastern Cape Province, South Africa, thus suggesting potential role for A. hebraeum and Riphicephalis species as vectors in the area, although, Borrelia species was not detected from the DNAs of the ticks. Occasioned by the high prevalence of rickettsial pathogens reported in this study, a systematic sero-prevalence study is proposed among the populations living in close proximity with domesticated animals as well as those with frequent exposure to vegetation, so as to establish the risk associated with tick bites in order to leverage appropriate legislative actions to be taken, hence reducing the tick-borne disease burden.

Owing to increase in demand for livestock in international trades, systematic surveillance is highly recommended, for the update of epidemiological data of these emerging and re-emerging arthropod-borne pathogens.

\section{Methods}

\section{Sampling Location}

Sample collection 
With the assistance of the animal health technicians and animal farm workers, one thousand two hundred $(1,200)$ feeding ticks were mechanically removed from farm animals (cattle, goats and sheep) into sterile 50 $\mathrm{mL}$ Nalgene tubes containing $70 \%$ ethanol. The six different sampling sites selected for this study are known geographical locations for animal husbandry in Amatole and O.R Tambo District Municipalities of the Eastern Cape, South Africa. There was adherence to the University of Fort Hare Animal Ethics Committee regulations on animal handling, throughout the sampling period. The collected ticks were transported to Applied and Environmental Microbiology Research Group (AEMREG) laboratory, in the Department of Biochemistry and Microbiology at University of Fort Hare for analyses. Collected ticks from different animals and locations were properly labelled in different tubes for easy identification and to avoid possible mix up.

\section{Tick identification and DNA extraction}

Upon arrival at the laboratory, identification of tick species was carried out based on morphologic criteria such as scutum formation, capitulum formation and limbs formation $22,23,24$. Upon identification, the arthropods were washed in sterile distilled water for about 3 to 4 times for total removal of ethanol into which they were collected, chopped with a sterile blade in petri dish containing phosphate buffer saline (PBS), then transferred into a $2 \mathrm{~mL}$ centrifuge tube and vortexed. Following this process, DNA extraction was carried out using the commercially available kit, Promega ReliaPrep ${ }^{\circledR}$ gDNA Tissue Miniprep System (Madison, USA), and the manufacture's protocol was strictly adhered to. Engorged ticks were processed individually while non-engorged ticks of the same species from same animal were processed by pooling using method previously described by James et al. ${ }^{25}$. Care was taken so that only ticks types collected from the same animal were processed as pools.

\section{Molecular Identification of tick species}

For the molecular identification of tick species previously identified morphologically, a fragment of $338 \mathrm{bp}$ of mitochondrial $12 \mathrm{~S}$ ribosomal RNA (rRNA) gene was amplified using a set of oligonucleotide 85F 12S [F:5'-TTAAGCTTTTCAGAGGAATTTGCTC-3'] and 2225 12S [R:5'

TTTAAGCTGCACCTTGAC TTAA-3']. Polymerase chain reaction was performed in a $25 \mu \mathrm{L}$ reaction mixture comprising of $14 \mu \mathrm{L}$ of master mix, $1 \mu \mathrm{L}$ each of $10 \mathrm{pmol} / \mathrm{L}$ of the forward and reverse primers, $4 \mu \mathrm{L}$ of RNase nuclease free water and $5 \mu \mathrm{L}$ of DNA template. The cycling conditions used for the amplification was as followed; initial denaturation at $94^{\circ} \mathrm{C}$ for $3 \mathrm{~min}$, followed by denaturation at $93^{\circ} \mathrm{C}$ for $30 \mathrm{sec}$, annealing at $51{ }^{\circ} \mathrm{C}$ for $30 \mathrm{sec}$, elongation at $72{ }^{\circ} \mathrm{C}$ for $60 \mathrm{sec}$ with a final elongation at $72{ }^{\circ} \mathrm{C}$ for $5 \mathrm{~min}$.

\section{Molecular Detection of Zoonotic Tick-Borne Bacterial Pathogens}

\section{Rickettsia species}

For the detection of Rickettsiae from the extracted DNA through polymerase chain reaction (PCR), a fragment of 631 bp of Rickettsia citrate encoding synthase $(g / t A)$ gene was amplified, using genusspecific primers [F:5'-TTTGTAGCTCTTCTCATCCTATGGC-3'] and [R:5'CCC AAGTTCCTTTAATA CTTCTTTGC$\left.3^{\prime}\right]$ as previously described by Pesquera et al. ${ }^{26}$. The reaction mixture containing $25 \mu \mathrm{L}$ volume consisted of 
$14 \mu \mathrm{L}$ of master mix, $1 \mu \mathrm{L}$ each of $10 \mathrm{pmol} / \mathrm{L}$ of the forward and reverse primers, $4 \mu \mathrm{L}$ of RNase nuclease free water and $5 \mu \mathrm{L}$ of DNA template. DNA amplification was carried using Biorad $\mathrm{T} 100^{\circledR}$ thermal cycler system, with the following cycling conditions; initial denaturation at $94{ }^{\circ} \mathrm{C}$ for $3 \mathrm{~min}$, followed by denaturation at $93^{\circ} \mathrm{C}$ for $30 \mathrm{sec}$, annealing at $49^{\circ} \mathrm{C}$ for $30 \mathrm{sec}$, elongation at $72{ }^{\circ} \mathrm{C}$ for $60 \mathrm{sec}$ with a final elongation at $72^{\circ} \mathrm{C}$ for $5 \mathrm{~min}$. Subsequently, all the positive samples were further subjected to screening for outer membrane protein $\mathrm{A}(\mathrm{ompA})$ and outer membrane protein $\mathrm{B}(\mathrm{ompB})$ which are structural protein that are imperative factors for rickettsial virulence and immunogen during infection ${ }^{13}$, by PCR using oligonucleotides [F:5'-ATGGCGAATATTTCTCCAAAA-3'] and [R:5'- GTTCCGTTAATGGCAGCATCT-3'] to generate $631 \mathrm{bp}$ of ompA gene, while [F: 5'-GTAACCGGAAGTAATCGTTTCGTAA-3'] and [R:5'-

GCTTTATAACCAGCTAAACCACC-3'] primers was used to generate $511 \mathrm{bp}$ of ompB gene. The PCR cycling conditions were as follow; initial denaturation at $94^{\circ} \mathrm{C}$ for $3 \mathrm{~min}$, followed by denaturation at $93^{\circ} \mathrm{C}$ for 30 sec, annealing at $48^{\circ} \mathrm{C}$ and $54^{\circ} \mathrm{C}$ for $30 \mathrm{sec}$ for ompA and ompB gene respectively, elongation at $72{ }^{\circ} \mathrm{C}$ for $60 \mathrm{sec}$ with a final elongation at $72^{\circ} \mathrm{C}$ for $5 \mathrm{~min}$ in a $25 \mu \mathrm{L}$ reaction mixture comprising $14 \mu \mathrm{L}$ of master mix, $1 \mu \mathrm{L}$ each of the forward and reverse primers, $4 \mu \mathrm{L}$ of RNase nuclease free water and $5 \mu \mathrm{L}$ of DNA template, as previously described by Noh et al. ${ }^{27}$ with modification of the annealing temperature.

\section{Borrelia species}

A two set of primers were used to amplify a partial region of flaB gene for Borrelia species; outward primer pairs of [F 5'-CCGTGCTAATTGTAGGGCTAA TAC-3'] and [R 5'-GAAGGTGCTGTAGCAGGTGCTGGCTGT$\left.3^{\prime}\right]$ while the inward primers of flaB [F 5'- AARGAATTGGCAGTTCAATC-3'] and [R 5'-

\section{GCATTTTCAATTTTAGCAAGTG}

ATG-3'] to eventually generate $380 \mathrm{bp}$ in a $25 \mu \mathrm{L}$ reaction volume containing $14 \mu \mathrm{L}$ of enzyme master mix, $1 \mu \mathrm{L}$ each of the forward and reverse primers, $4 \mu \mathrm{L}$ of RNase nuclease free water and $5 \mu \mathrm{L}$ of DNA template, under a thermo-cycling conditions of $3 \mathrm{~min}$ at $94^{\circ} \mathrm{C}$ for initial denaturation, followed by denaturation at 93 ${ }^{\circ} \mathrm{C}$ for $30 \mathrm{sec}$, annealing at $55^{\circ} \mathrm{C}$ and $52^{\circ} \mathrm{C}$ for $30 \mathrm{sec}$, for the outward and inward flaB gene respectively, elongation at $72{ }^{\circ} \mathrm{C}$ for $60 \mathrm{sec}\left(40\right.$ cycles of amplification) with a final elongation at $72{ }^{\circ} \mathrm{C}$ for $5 \mathrm{~min}$. All the PCR products were analyzed in $1 \%$ agarose gel electrophoresis in $0.5 \%$ TBE buffer, followed by staining with ethidium bromide. The gel was visualized under UV transilluminator (Samson et al., 2004). A negative control was included in the PCR so as to detect false positive or any possibility of cross contamination. Bidirectional sequencing was carried on all the positive ompB amplicons using ABI3500xl automated DNA sequencer with a $50 \mathrm{~cm}$ Capillary array and POP7 (all supplied by Applied Biosystems).

\section{Sequence Editing and Blast Search}

Nucleotide sequences for both forward and reversed strands were assembled together and edited to generate consensus sequences for each positive PCR product, using the Geneious programme version $10.1 .2^{28}$.

The consensus sequences data generated after editing were subjected to BLAST program in GenBank for homology search with other curated sequences (http://blast.ncbi.nlm.nih.gov). The search parameters were set on highly similar sequences, hence, Borrelia spp, and Rickettsia spp. were chosen separately as the 
organism option. Sequences with a percentage similarity above $97 \%$ were downloaded for phylogenetic analysis.

\section{List Of Abbreviations}

TBDs Tick Borne Diseases

OMP Outer Membrane Protein

\section{Declarations}

Ethics approval and consent to participate

Ethical clearance for the study was obtained from the University of Fort Hare Research and Ethics Committee (reference number: OBI013)and permission to collect samples was sought from farmers and appropriate authority prior to sample collection

Consent for publication

Not applicable

Availability of data and materials

The datasets generated and/or analysed during the current study are available in the NCBI repository, [https://www.ncbi.nlm.nih.gov/nuccore/MK347112-MK347185]

Competing interests

The authors declare that they have no competing interests

Funding

The authors are grateful to South African Medical Research Council (SAMRC) for her financial support towards collection of samples and analysis of this study.

Authors' contributions

Adelabu OA; designed, conducted, analysed and interpreted the results of the study. Iweriebor CB; supervised, co-analysed the results and corrected the manuscript. Okoh Al; provided the materials and edited the manuscript. Obi CL; sourced for the funding and corrected the manuscript.

Acknowledgements

Not applicable

\section{References}


[1] Sheela AM, Ghermandi A, Vineetha P, Sheeja RV, Justus J, Ajayakrishna K. Assessment of relation of land use characteristics with vector-borne diseases in tropical areas. Land Use Policy. 2017 Apr 1;63:369-80.

[2] Nicholson WL, Sonenshine DE, Noden BH, Brown RN. Ticks (Ixodida). InMedical and veterinary entomology 2019 Jan 1 (pp. 603-672). Academic Press.

[3] de la Fuente J, Estrada-Pena A, Venzal JM, Kocan KM, Sonenshine DE. Overview: ticks as vectors of pathogens that cause disease in humans and animals. Front Biosci. 2008 May 1;13(13):6938-46.

[4] Kahl O. Hard ticks as vectors-some basic issues. Wiener klinische Wochenschrift. 2018 Aug 1;130(1516):479-83.

[5] Leulmi H, Aouadi A, Bitam I, Bessas A, Benakhla A, Raoult D, Parola P. Detection of Bartonella tamiae, Coxiella burnetii and rickettsiae in arthropods and tissues from wild and domestic animals in northeastern Algeria. Parasites \& vectors. 2016 Dec;9(1):27.

[6] Sormunen JJ, Penttinen R, Klemola T, Hänninen J, Vuorinen I, Laaksonen M, Sääksjärvi IE, Ruohomäki K, Vesterinen EJ. Tick-borne bacterial pathogens in southwestern Finland. Parasites \& vectors. 2016 Dec;9(1):168.

[7] Venclíková K, Mendel J, Betášová L, Blažejová H, Jedličková P, Straková P, Hubálek Z, Rudolf I. Neglected tick-borne pathogens in the Czech Republic, 2011-2014. Ticks and tick-borne diseases. 2016 Feb 1;7(1):107-12.

[8] Potkonjak A, Gutiérrez R, Savić S, Vračar V, Nachum-Biala Y, Jurišić A, Kleinerman G, Rojas A, Petrović A, Baneth G, Harrus S. Molecular detection of emerging tick-borne pathogens in Vojvodina, Serbia. Ticks and tick-borne diseases. 2016 Feb 1;7(1):199-203.

[9] Bichara D, Iggidr A, Smith L. Multi-stage vector-borne zoonoses models: A global analysis. Bulletin of mathematical biology. 2018 Jul 1;80(7):1810-48.

[10] Abdad MY, Abdallah RA, Fournier PE, Stenos J, Vasoo S. A concise review of the epidemiology and diagnostics of rickettsioses: Rickettsia and Orientia spp. Journal of clinical microbiology. 2018 Aug 1;56(8):e01728-17.

[11] Ericsson CD, Jensenius M, Fournier PE, Raoult D. Rickettsioses and the international traveler. Clinical infectious diseases. 2004 Nov 15;39(10):1493-9.

[12] Shapiro MR, Fritz CL, Tait K, Paddock CD, Nicholson WL, Abramowicz KF, Karpathy SE, Dasch GA, Sumner JW, Adem PV, Scott JJ. Rickettsia 364D: a newly recognized cause of eschar-associated illness in California. Clinical infectious diseases. 2010 Feb 15;50(4):541-8.

[13] Johnson DI, Beck. Bacterial pathogens and their virulence factors. Cham: Springer; 2018. 
[14] Legendre KP, Macaluso KR. Rickettsia felis: a review of transmission mechanisms of an emerging pathogen. Tropical medicine and infectious disease. 2017 Dec;2(4):64.

[15] Kelly DJ, Richards AL, Temenak J, Strickman D, Dasch GA. The past and present threat of rickettsial diseases to military medicine and international public health. Clinical infectious diseases. 2002 Jun 15;34(Supplement_4):S145-69.

[16] Jiang J, Maina AN, Knobel DL, Cleaveland S, Laudisoit A, Wamburu K, Ogola E, Parola P, Breiman RF, Njenga MK, Richards AL. Molecular detection of Rickettsia felis and Candidatus Rickettsia asemboensis in fleas from human habitats, Asembo, Kenya. Vector-Borne and zoonotic diseases. 2013 Aug 1;13(8):550-8.

[17] Euzeby JP. List of prokaryotic names with standing in nomen-clature: genus Legionella. http://www. bacterio. cict. fr/l/legionella. html. 2013.

[18] Cutler SJ, Ruzic-Sabljic E, Potkonjak A. Emerging borreliae-Expanding beyond Lyme borreliosis. Molecular and cellular probes. 2017 Feb 1;31:22-7.

[19] Wang G, Villafuerte P, Zhuge J, Visintainer P, Wormser GP. Comparison of a quantitative PCR assay with peripheral blood smear examination for detection and quantitation of Babesia microti infection in humans. Diagnostic microbiology and infectious disease. 2015 Jun 1;82(2):109-113.

[20] Regunath H, Rojas-Moreno C, Olano JP, Hammer RD, Salzer W. Early diagnosis of E hrlichia ewingii infection in a lung transplant recipient by peripheral blood smear. Transplant Infectious Disease. 2017 Apr;19(2):e12652.

[21] Essbauer S, Hofmann M, Kleinemeier C, Wölfel S, Matthee S. Rickettsia diversity in southern Africa: a small mammal perspective. Ticks and tick-borne diseases. 2018 Feb 1;9(2):288-301.

[22] Fourie LJ, Novellie PA, Williams EJ, Horak IG. Parasites of domestic and wild animals in South Africa. XXVI. The mosaic of ixodid tick infestations on birds and mammals in the Mountain Zebra National Park.

[23] Horak IG. Parasites of domestic and wild animals in South Africa. XXXVII. Ixodid ticks on cattle on Kikuyu grass pastures and in Valley Bushveld in the Eastern Cape Province.

[24] Walker DH, Bouyer DH. Rickettsia and orientia. InManual of Clinical Microbiology, Eleventh Edition 2015 Jun 1 (pp. 1122-1134). American Society of Microbiology.

[25] Jmes MC, Gilbert L, Bowman AS, Forbes KJ. The heterogeneity, distribution, and environmental associations of Borrelia burgdorferi sensu lato, the agent of Lyme borreliosis, in Scotland. Frontiers in public health. 2014 Aug 28;2:129.

[26] Pesquera C, Portillo A, Palomar AM, Oteo JA. Investigation of tick-borne bacteria (Rickettsia spp., Anaplasma spp., Ehrlichia spp. and Borrelia spp.) in ticks collected from Andean tapirs, cattle and vegetation from a protected area in Ecuador. Parasites \& vectors. 2015 Dec;8(1):46. 
[27] Noh Y, Lee YS, Kim HC, Chong ST, Klein TA, Jiang J, Richards AL, Lee HK, Kim SY. Molecular detection of Rickettsia species in ticks collected from the southwestern provinces of the Republic of Korea. Parasites \& vectors. 2017 Dec;10(1):20.

[28] Kearse M, Moir R, Wilson A, Stones-Havas S, Cheung M, Sturrock S, Buxton S, Cooper A, Markowitz S, Duran C, Thierer T. Geneious Basic: an integrated and extendable desktop software platform for the organization and analysis of sequence data. Bioinformatics. 2012 Apr 27;28(12):1647-9.

[29] Kumar S, Stecher G, Tamura K. MEGA7: molecular evolutionary genetics analysis version 7.0 for bigger datasets. Molecular biology and evolution. 2016 Mar 22;33(7):1870-4.

[30] Tomassone L, Portillo A, Nováková M, De Sousa R, Oteo JA. Neglected aspects of tick-borne rickettsioses. Parasites \& vectors. 2018 Dec;11(1):263.

[31] Halajian A, Palomar AM, Portillo A, Heyne H, Romero L, Oteo JA. Detection of zoonotic agents and a new Rickettsia strain in ticks from donkeys from South Africa: Implications for travel medicine. Travel medicine and infectious disease. 2018 Nov 1;26:43-50.

[32] Yawa M, Nyangiwe N, Muchenje V, Kadzere CT, Mpendulo TC, Marufu MC. Ecological preferences and seasonal dynamics of ticks (Acari: Ixodidae) on and off bovine hosts in the Eastern Cape Province, South Africa. Experimental and Applied Acarology. 2018 Mar 1;74(3):317-28.

[33] Horak IG, Heyne H, Williams R, Gallivan GJ, Spickett AM, Bezuidenhout JD, Estrada-Peña A. The Ixodid Ticks (Acari: Ixodidae) of Southern Africa. Springer; 2018 Feb 14.

[34] Parola P, Paddock CD, Socolovschi C, Labruna MB, Mediannikov O, Kernif T, Abdad MY, Stenos J, Bitam I, Fournier PE, Raoult D. Update on Tick-Borne Rickettsioses around the World: a Geographic Approach. Clinical microbiology reviews. 2014 Jan;27(1):166.

[35] García-García JC, Portillo A, Núñez MJ, Santibáñez S, Castro B, Oteo JA. A patient from Argentina infected with Rickettsia massiliae. The American journal of tropical medicine and hygiene. $2010 \mathrm{Apr}$ 1;82(4):691-2.

[36] Moraes-Filho J, Krawczak FS, Costa FB, Soares JF, Labruna MB. Comparative evaluation of the vector competence of four South American populations of the Rhipicephalus sanguineus group for the bacterium Ehrlichia canis, the agent of canine monocytic ehrlichiosis. PLoS One. 2015 Sep 28;10(9):e0139386.

[37] Dantas-Torres F, Chomel BB, Otranto D. Ticks and tick-borne diseases: a One Health perspective. Trends in parasitology. 2012 Oct 1;28(10):437-46.

[38] Yu Z, Wang H, Wang T, Sun W, Yang X, Liu J. Tick-borne pathogens and the vector potential of ticks in China. Parasites \& vectors. 2015 Dec;8(1):24.

[39] Márquez FJ. Spotted fever group Rickettsia in ticks from southeastern Spain natural parks. Experimental and Applied Acarology. 2008 Aug 1;45(3-4):185-94. 
[40] Duh D, Punda-Polic V, Avsic-Zupanc T, Bouyer D, Walker DH, Popov VL, Jelovsek M, Gracner M, Trilar T, Bradaric N, Kurtti TJ. Rickettsia hoogstraalii sp. nov., isolated from hard-and soft-bodied ticks. International journal of systematic and evolutionary microbiology. 2010 Apr 1;60(4):977-84.

[41] Chochlakis D, loannou I, Sandalakis V, Dimitriou T, Kassinis N, Papadopoulos B, Tselentis Y, Psaroulaki A. Spotted fever group Rickettsiae in ticks in Cyprus. Microbial ecology. 2012 Feb 1;63(2):314-23.

[42] Chisu V, Leulmi H, Masala G, Piredda M, Foxi C, Parola P. Detection of Rickettsia hoogstraalii, Rickettsia helvetica, Rickettsia massiliae, Rickettsia slovaca and Rickettsia aeschlimannii in ticks from Sardinia, Italy. Ticks and tick-borne diseases. 2017 Mar 1;8(3):347-52.

[43] Gofton AW, Doggett S, Ratchford A, Oskam CL, Paparini A, Ryan U, Irwin P. Bacterial profiling reveals novel "Ca. Neoehrlichia", Ehrlichia, and Anaplasma species in Australian human-biting ticks. PloS one. 2015 Dec 28;10(12):e0145449.

[44] Jiang BG, Jia N, Jiang JF, Zheng YC, Chu YL, Jiang RR, Wang YW, Liu HB, Wei R, Zhang WH, Li Y. Borrelia miyamotoi infections in humans and ticks, northeastern China. Emerging infectious diseases. 2018 Feb;24(2):236.

[45] Sarih M, Socolovschi C, Boudebouch N, Hassar M, Raoult D, Parola P. Spotted fever group rickettsiae in ticks, Morocco. Emerging infectious diseases. 2008 Jul;14(7):1067.

[46] Kolo AO, Sibeko-Matjila KP, Maina AN, Richards AL, Knobel DL, Matjila PT. Molecular detection of zoonotic rickettsiae and Anaplasma spp. in domestic dogs and their ectoparasites in Bushbuckridge, South Africa. Vector-Borne and Zoonotic Diseases. 2016 Apr 1;16(4):245-52.

[47] Angerami RN, Krawczak FS, Nieri-Bastos FA, Santos F, Medorima C, Resende MR, Labruna MB. First report of African tick-bite fever in a South American traveler. SAGE Open Medical Case Reports. 2018 May 11;6:2050313X18775301.

[48] Ndip L, Ndip R, Walker D, McBride J. Human Ehrlichioses and Rickettsioses in Cameroon. InCurrent Topics in Tropical Medicine 2012 Mar 16. IntechOpen.

[49] Keller C, Krüger A, Schwarz NG, Rakotozandrindrainy R, Rakotondrainiarivelo JP, Razafindrabe T, Derschum H, Silaghi C, Pothmann D, Veit A, Hogan B. High detection rate of Rickettsia africae in Amblyomma variegatum but low prevalence of anti-rickettsial antibodies in healthy pregnant women in Madagascar. Ticks and tick-borne diseases. 2016 Feb 1;7(1):60-5.

[50] Vogel H, Foley J, Fiorello CV. Rickettsia africae and novel rickettsial strain in Amblyomma spp. ticks, Nicaragua, 2013. Emerging infectious diseases. 2018 Feb;24(2):385.

[51] MCQUISTON JH, PADDOCK CD, SINGLETON JR JO, WHEELING JT, ZAKI SR, CHILDS JE. Imported spotted fever rickettsioses in United States travelers returning from Africa: a summary of cases confirmed by laboratory testing at the Centers for Disease Control and Prevention, 1999-2002. The American journal of tropical medicine and hygiene. 2004 Jan 1;70(1):98-101. 
[52] Mediannikov, O., Diatta, G., Fenollar, F., Sokhna, C., Trape, J.F. and Raoult, D., 2010. Tick-borne rickettsioses, neglected emerging diseases in rural Senegal., PLoS Neglected Tropical Diseases, 4(9), p.e821.

[53] Cicculli V, de Lamballerie X, Charrel R, Falchi A. First molecular detection of Rickettsia africae in a tropical bont tick, Amblyomma variegatum, collected in Corsica, France. Experimental and Applied Acarology. 2019 Feb 1;77(2):207-14.

[54] Kernif T, Djerbouh A, Mediannikov O, Ayach B, Rolain JM, Raoult D, Parola P, Bitam I. Rickettsia africae in Hyalomma dromedarii ticks from sub-Saharan Algeria. Ticks and tick-borne diseases. 2012 Dec 1;3(56):377-9.

[55] Zammarchi L, Farese A, Trotta M, Amantini A, Raoult D, Bartoloni A. Rickettsia africae infection complicated with painful sacral syndrome in an Italian traveller returning from Zimbabwe. International Journal of Infectious Diseases. 2014 Dec 1;29:194-6.

[56] Paddock CD, Finley RW, Wright CS, Robinson HN, Schrodt BJ, Lane CC, Ekenna O, Blass MA, Tamminga $\mathrm{CL}$, Ohl CA, McLellan SL. Rickettsia parkeri rickettsiosis and its clinical distinction from Rocky Mountain spotted fever. Clinical Infectious Diseases. 2008 Nov 1;47(9):1188-96.

[57] Biggs HM, Barton Behravesh C, Bradley KK, Dahlgren FS, Drexler NA, Dumler JS, Folk SM, Kato CY, Ryan $\mathrm{R}$, Levin ML, Massung RF. Diagnosis and management of tickborne rickettsial diseases: Rocky Mountain spotted fever and other spotted fever group rickettsioses, ehrlichioses, and anaplasmosis-United States: a practical guide for health care and public health professionals.

[58] Romer Y, Seijo AC, Crudo F, Nicholson WL, Varela-Stokes A, Lash RR, Paddock CD. Rickettsia parkeri rickettsiosis, Argentina. Emerging infectious diseases. 2011 Jul;17(7):1169.

[59] Souza U, Dall'Agnol B, Michel T, Webster A, Weck B, Doyle R, Kasper CB, Soares J, Martins JR, Trigo TC, Ott R. Molecular survey of Rickettsia spp. in the Neotropical deer tick Haemaphysalis juxtakochi from Brazilian Pampa. Parasitology research. 2018 Oct 1;117(10):3293-8.

[60] Romer Y, Nava S, Govedic F, Cicuttin G, Denison AM, Singleton J, Kelly AJ, Kato CY, Paddock CD. Rickettsia parkeri rickettsiosis in different ecological regions of Argentina and its association with Amblyomma tigrinum as a potential vector. The American journal of tropical medicine and hygiene. 2014 Dec 3;91(6):1156-60.

[61] Faccini-Martínez ÁA, Félix ML, Armua-Fernandez MT, Venzal JM. An autochthonous confirmed case of Rickettsia parkeri rickettsiosis in Uruguay. Ticks and tick-borne diseases. 2018 Mar 1;9(3):718-9.

[62] Weck B, Dall'Agnol B, Souza U, Webster A, Stenzel B, Klafke G, Martins JR, Reck J. Spotted fever group Rickettsia in the Pampa biome, Brazil, 2015-2016. Emerging infectious diseases. 2016 Nov;22(11):2014. 
[63] Fournier PE, Tissot-Dupont $\mathrm{H}$, Gallais H, Raoult DR. Rickettsia mongolotimonae: a rare pathogen in France. Emerging infectious diseases. 2000 May;6(3):290.

[64] Angelakis E, Richet H, Raoult D. Rickettsia sibirica mongolitimonae infection, France, 2010-2014. Emerging infectious diseases. 2016 May;22(5):880.

[65] Psaroulaki A, Germanakis A, Gikas A, Scoulica E, Tselentis Y. Simultaneous detection of "Rickettsia mongolotimonae" in a patient and in a tick in Greece. Journal of clinical microbiology. $2005 \mathrm{Jul}$ 1;43(7):3558-9.

[66] Cordier C, Tattevin P, Leyer C, Cailleaux M, Raoult D, Angelakis E. Rickettsia sibirica mongolitimonae infection, Sri Lanka. The Journal of Infection in Developing Countries. 2017 Sep 5;11(08):668-71.

[67] Nouchi A, Monsel G, Jaspard M, Jannic A, Angelakis E, Caumes E. Rickettsia sibirica mongolitimonae infection in a woman travelling from Cameroon: a case report and review of the literature. Journal of travel medicine. 2017 Dec 27;25(1):tax074.

[68] Gaillard T, Briolant S, Madamet M, Pradines B. The end of a dogma: the safety of doxycycline use in young children for malaria treatment. Malaria journal. 2017 Dec;16(1):148.

[69] Pretorius AM, Birtles RJ. Rickettsia mongolotimonae infection in South Africa. Emerging infectious diseases. 2004 Jan;10(1):125.

[70] Horak IG, Fourie LJ, Heyne H, Walker JB, Needham GR. Ixodid ticks feeding on humans in South Africa: with notes on preferred hosts, geographic distribution, seasonal occurrence and transmission of pathogens. Experimental \& applied acarology. 2002 Jan 1;27(1-2):113-36.

[71] Kakumanu ML, Ponnusamy L, Sutton HT, Meshnick SR, Nicholson WL, Apperson CS. Development and validation of an improved PCR method using the 23S-5S intergenic spacer for detection of rickettsiae in Dermacentor variabilis ticks and tissue samples from humans and laboratory animals. Journal of clinical microbiology. 2016 Apr 1;54(4):972-9.

[72] Qiu Y, Nakao R, Thu MJ, Akter S, Alam MZ, Kato S, Katakura K, Sugimoto C. Molecular evidence of spotted fever group rickettsiae and Anaplasmataceae from ticks and stray dogs in Bangladesh. Parasitology research. 2016 Mar 1;115(3):949-55.

[73] Abdad MY, Abdallah RA, El Karkouri K, Beye M, Stenos J, Owen H, Unsworth N, Robertson I, Blacksell SD, Nguyen TT, Nappez C. Rickettsia gravesii sp. nov.: a novel spotted fever group rickettsia in Western Australian Amblyomma triguttatum triguttatum ticks. International journal of systematic and evolutionary microbiology. 2017 Aug 31;67(9):3156-61.

[74] Tshokey T, Stenos J, Durrheim DN, Eastwood K, Nguyen C, Graves SR. Seroprevalence of rickettsial infections and Q fever in Bhutan. PLoS neglected tropical diseases. 2017 Nov 27;11(11):e0006107. 
[75] Salgado Lynn M, William T, Tanganuchitcharnchai A, Jintaworn S, Thaipadungpanit J, Lee M, Jalius C, Daszak P, Goossens B, Hughes T, Blacksell S. Spotted fever rickettsiosis in a wildlife researcher in Sabah, Malaysia: a case study. Tropical medicine and infectious disease. 2018 Mar;3(1):29.

[76] Labruna MB, Pacheco RC, Richtzenhain LJ, Szabo MP. Isolation of Rickettsia rhipicephali and Rickettsia bellii from Haemaphysalis juxtakochi ticks in the state of Sao Paulo, Brazil. Appl. Environ. Microbiol.. 2007 Feb 1;73(3):869-73.

[77] Conti-Díaz IA, Moraes-Filho J, Pacheco RC, Labruna MB. Serological evidence of Rickettsia parkeri as the etiological agent of rickettsiosis in Uruguay. Revista do Instituto de Medicina Tropical de São Paulo. 2009 Dec;51(6):337-9.

[78] Mancini F, Ciccozzi M, Lo Presti A, Cella E, Giovanetti M, Di Luca M, Toma L, Bianchi R, Khoury C, Rezza G, Ciervo A. Characterization of spotted fever group Rickettsiae in ticks from a city park of Rome, Italy. Annali dell'Istituto superiore di sanita. 2015;51:284-90.

[79] Evans S, Adcox H, VieBrock L, Green R, Luce-Fedrow A, Chattopadhyay S, Jiang J, Marconi R, Paris D, Richards A, Carlyon J. Outer Membrane Protein A Conservation among Orientia tsutsugamushi Isolates Suggests Its Potential as a Protective Antigen and Diagnostic Target. Tropical medicine and infectious disease. 2018 Jun;3(2):63.

[80] Stewart A, Armstrong M, Graves S, Hajkowicz K. Rickettsia australis and Queensland tick typhus: A rickettsial spotted fever group infection in Australia. The American journal of tropical medicine and hygiene. 2017 Jul 12;97(1):24-9.

[81] Hinckley AF, Connally NP, Meek JI, Johnson BJ, Kemperman MM, Feldman KA, White JL, Mead PS. Lyme disease testing by large commercial laboratories in the United States. Clinical Infectious Diseases. 2014 May 30;59(5):676-81.

[82] Stromdahl EY, Hickling GJ. Beyond Lyme: Aetiology of tick-borne human diseases with emphasis on the South-Eastern United States. Zoonoses and public health. 2012 Sep;59:48-64.

[83] Kimita G, Mutai B, Nyanjom SG, Wamunyokoli F, Waitumbi J. Phylogenetic Variants of Rickettsia africae, and Incidental Identification of" Candidatus Rickettsia Moyalensis" in Kenya. PLoS neglected tropical diseases. $2016 \mathrm{Jul}$ 7;10(7):e0004788.

[84] Bitam I, Parola P, Matsumoto K, Rolain JM, Baziz B, Boubidi SC, Harrat Z, Belkaid M, Raoult D. First molecular detection of R. conorii, R. aeschlimannii, and R. massiliae in ticks from Algeria. Annals of the New York Academy of Sciences. 2006 Oct;1078(1):368-72.

[85] Bacellar F, Beati L, Franca A, Pocas J, Regnery R, Filipe A. Israeli spotted fever rickettsia (Rickettsia conorii complex) associated with human disease in Portugal. Emerging infectious diseases. 1999 Nov;5(6):835. 
[86] Jado I, Oteo JA, Aldámiz M, Gil H, Escudero R, Ibarra V, Portu J, Portillo A, Lezaun MJ, García-Amil C, Rodríguez-Moreno I. Rickettsia monacensis and human disease, Spain. Emerging infectious diseases. 2007 Sep;13(9):1405.

[87] Chochlakis D, Germanakis A, Chaliotis G, Kapetanaki S, Kalogeraki L, Gkika E, Partalis N, Polymili G, Tselentis Y, Psaroulaki A. Potential exposure of humans to Rickettsia felis in Greece. Acta tropica. 2018 Feb 1;178:40-5.

[88] Fournier PE, Roux V, Caumes E, Donzel M, Raoult D. Outbreak of Rickettsia africae infections in participants of an adventure race in South Africa. Clinical infectious diseases. 1998 Aug 1;27(2):316-23.

[89] Mtshali K, Khumalo ZT, Nakao R, Grab DJ, Sugimoto C, Thekisoe OM. Molecular detection of zoonotic tick-borne pathogens from ticks collected from ruminants in four South African provinces. Journal of Veterinary Medical Science. 2015:15-0170.

[90] Iweriebor BC, Igwaran A, Adegborioye AA, Mmbaga EJ, Okoh Al and Obi LC. Molecular screening of ticks for the presence of Rickettsia species: A public health concern. Asian Pacific Journal of Tropical Disease. 2017, 7(4):199-204.

[91] Maclvor, L.G., 1987. Foot abscess in goats in relation to the seasonal abundance of adult Amblyomma hebraeum and adult Rhipicephalus glabroscutatum (Acari: Ixodidae). Journal of the South African Veterinary Association, 58(3), pp.113-118.

[92] Sungirai M, Madder M, Moyo DZ, De Clercq P, Abatih EN. An update on the ecological distribution of the Ixodidae ticks in Zimbabwe. Experimental and Applied Acarology. 2015 Jun 1;66(2):269-80.

[93] Cherry CC, Denison AM, Kato CY, Thornton K, Paddock CD. Diagnosis of Spotted Fever Group Rickettsioses in US Travelers Returning from Africa, 2007-2016. The American journal of tropical medicine and hygiene. 2018 Jul 5;99(1):136-42

\section{Tables}

\section{Table 1}


Tick species

\section{Cattle Goat Sheep}
A. hebraeum
235
80
20
$335(27.9)$

Rh. decoloratus

129

70

25

224(18.7)

Rh.sanguineus

0

15

5

$20(1.7)$

Rh. eversti eversti 140

40

20

$200(16.7)$

Rh. microplus

70

40

20

$130(10.8)$

Rh.appendiculatus 139

95

40

$274(22.8)$

Rh. zambeziensis 5

0

0

$5(0.4)$

H.spinulosa

0

12

0

$12(1.0)$

Total

718

352

130

1,200

\section{Table 2}




\begin{tabular}{llll}
\hline Sample & Blast Homology & Reference & GenBank Accession Number \\
& (\%) & species &
\end{tabular}

D219, D189 $100.0 \quad$ R.africae $\quad$ KY124259,KX227790

B10, B26, 97.1-99.1 Rickettsia sp. KX227788, KT032137

D187

B12, B17, 96.8-99.8 R.parkeri, KY113111, CP003341, KY124259,

B20, B24, R.sibrica KY113111, HM050273

B218

B13, B14, $96.7 \quad$ R.conorii $\quad$ AF123726

B15, B16,

B22, D183,

D186, D197,

D200

B24, D213, $99.1 \quad$ R.peacockii, KJ675445,JX683122

D214, D215 R.slovaca

B240,D211 96.0 Rickettsia sp. KT032141, KT032136,KX227791

D191, D216, $97.6 \quad$ R.slovaca KJ663756,HQ232242,CP002428,AF123723

D127

D219 $\quad$ R.honei, $\quad$ AF123724, CP006010,AF123719

$R$,rickettsi,

R,rhipicephalis

D221 $\quad 97.4 \quad$ Candidatus $\quad$ KY233284, KX227791,AF123722

R.barbariae, $R$,

slovaca,

R.sibrica

D22

97.9-99.3

R.peacockii, CP001227,

HQ232277,CP003308, 


\section{R.philipii,}

\section{R.rhiphicephali}

\section{Figures}

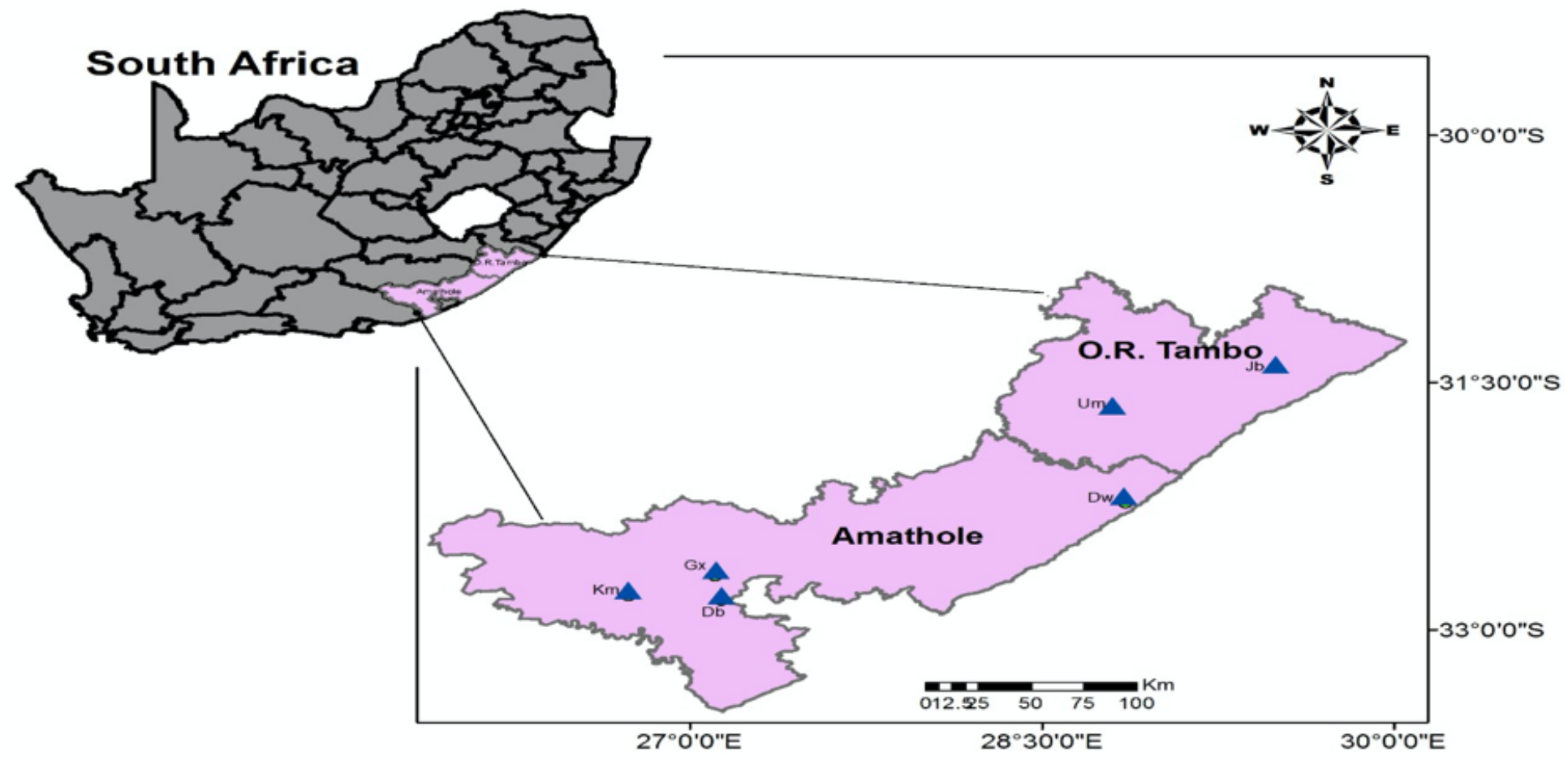

\section{Figure 1}

The map showing the geographical location of the sampling sites with their coordinates; Debe $(\mathrm{Db})=$ $32^{\circ} 52^{\prime} 11.852^{\prime \prime S}, 27^{\circ} 1^{\prime} 14.171$ "E; Gxulu (Gx) = 3240'26.702"S, 276'19.591"E; KwaMemela (Km) = $32^{\circ} 47^{\prime} 38.497 " \mathrm{~S}, 26^{\circ} 44^{\prime} 10.889$ "E; Dwesa (Dw) = 32¹3'50.916"S, 2851'16.135"E; Umtata (Um) = $31^{\circ} 39^{\prime} 26.69 " \mathrm{~S}, 28^{\circ} 48^{\prime} 0.194^{\prime \prime E}$; Jambini $(\mathrm{Jb})=31^{\circ} 23^{\prime} 36.856 " \mathrm{~S}, 29^{\circ} 29^{\prime} 46.921^{\prime \prime E}$. Map created using ArcMap 10.5 .1 


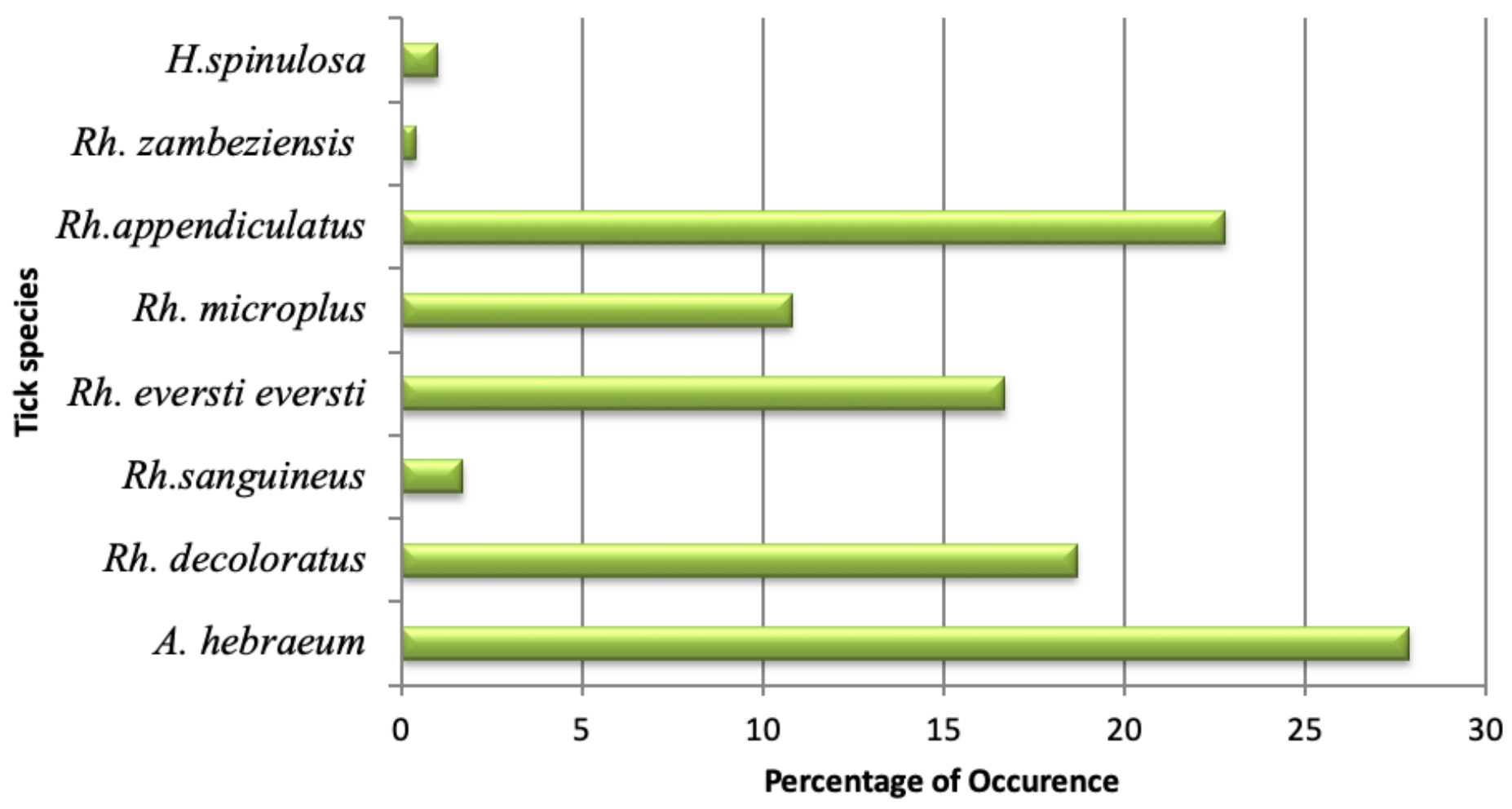

Figure 2

The prevalence of tick species collected in the study. The figure shows the overall prevalence of tick species collected in all the sampling sites. 

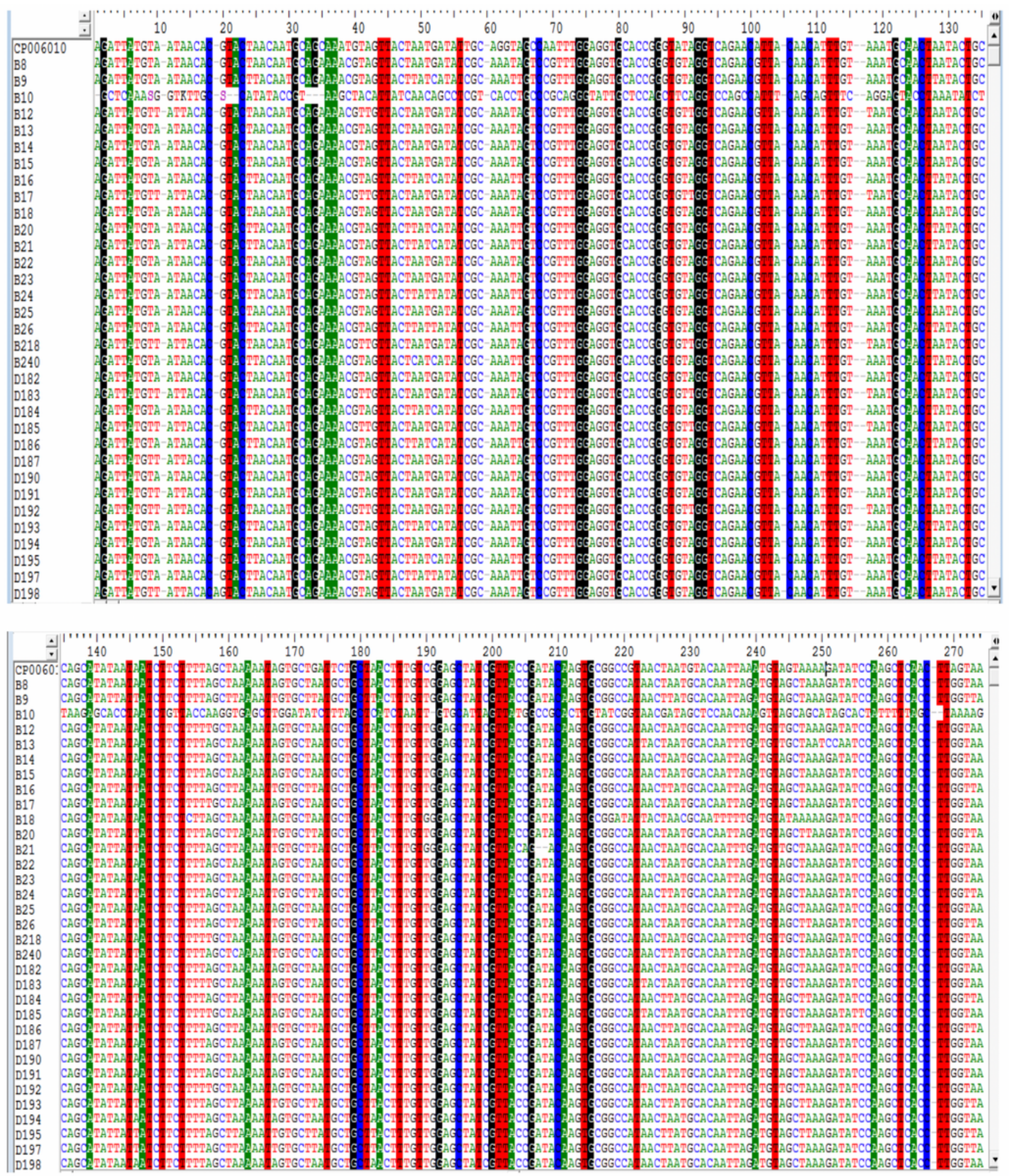

\section{Figure 3}

Nucleotide sequence alignment of the sequences in the polymorphic region of the ompB gene of Rickettsia spp. with Rickettsia rickettsii serving as the reference sequence along with generated sequences in this study. Nucleotides that are identical for all species are highlighted in colour while those that vary between species and can be used for differentiation are not highlighted. 


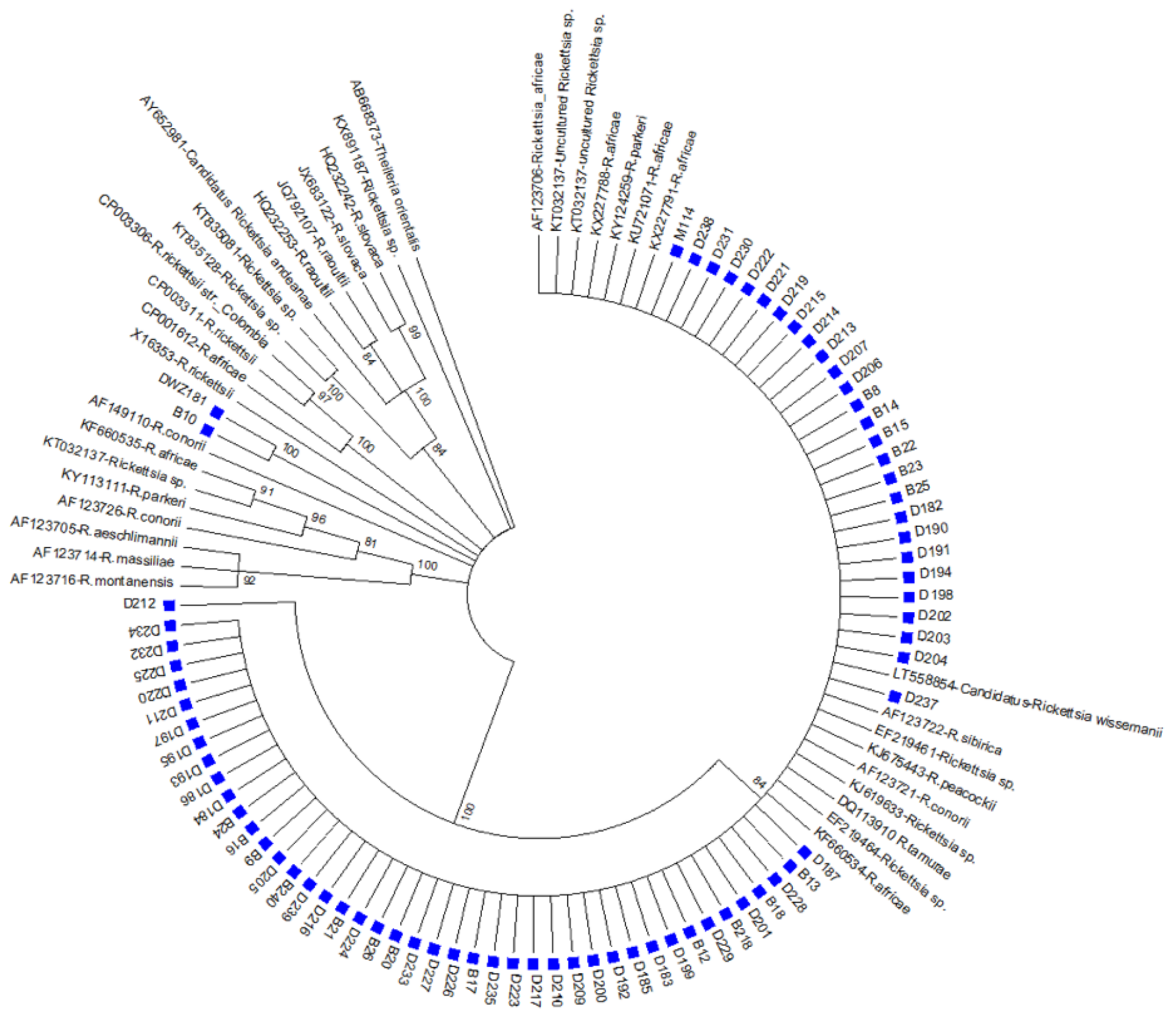

\section{Figure 4}

Evolutionary relationships of different Rickettsia spp. based on the nucleotide sequence of ompB gene. The evolutionary history was inferred using the Neighbor-Joining method. The confidence probability (multiplied by 100) that the interior branch length is greater than 0 , as estimated using the bootstrap test 1000 replicates is shown next to the branches. The evolutionary distances were computed using the p-distance method and are in the units of the number of base differences per site. Evolutionary analyses were conducted in MEGA7 29(Kumar et al., 2016). 


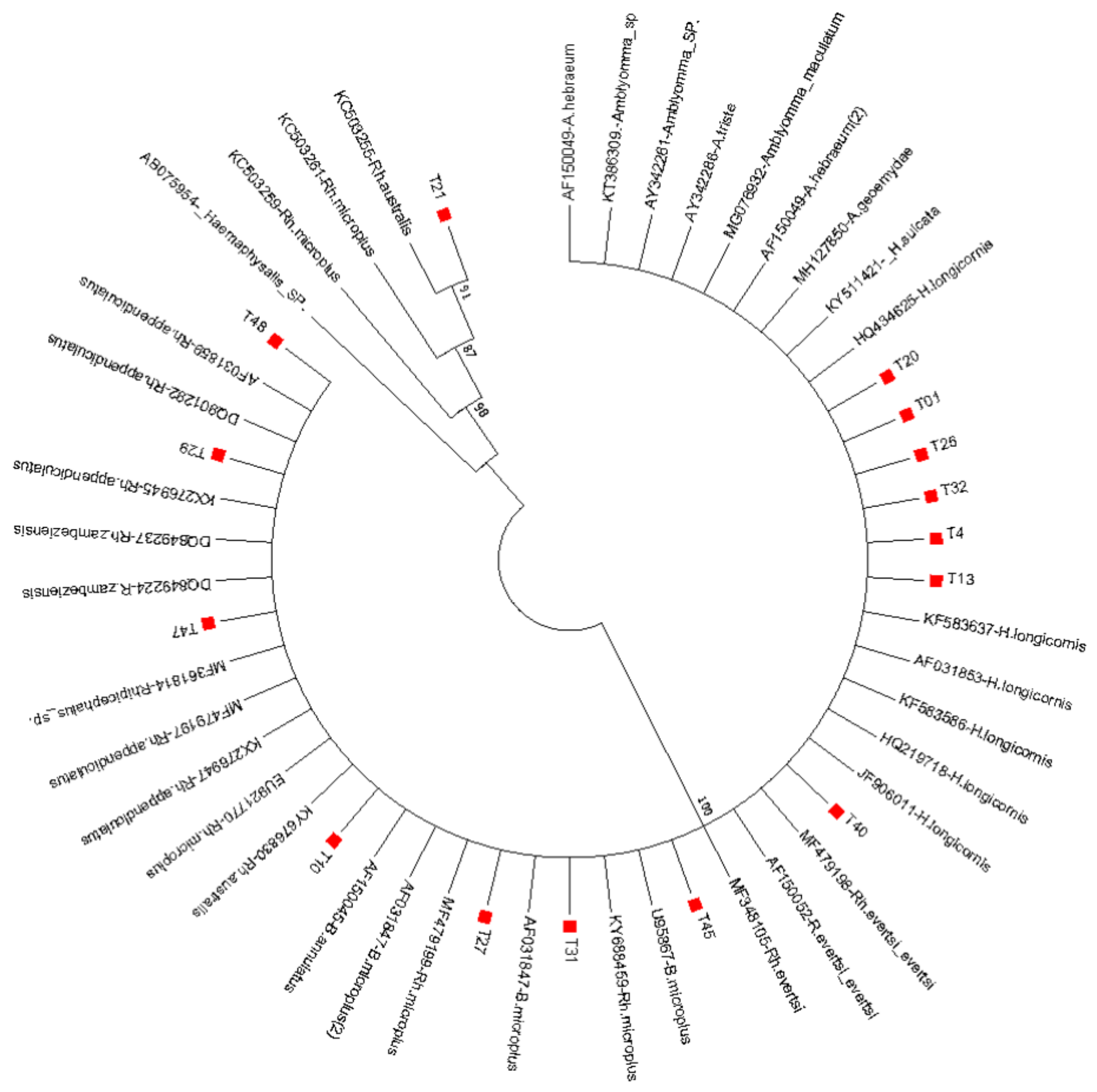

Figure 5

Evolutionary relationships of tick species based on Nucleotide sequences of mitochondrial $12 \mathrm{~S}$ ribosomal RNA gene. The bootstrap consensus tree inferred from 1000 replicates was taken to represent the evolutionary history. The evolutionary distances were computed using the Maximum Composite Likelihood method. Evolutionary analyses were conducted in MEGA7 29 